\title{
ダイナミックミキシング法による $\mathrm{Ti}-\mathrm{Al}-\mathrm{N}$ 薄膜の形成*
}

\author{
鷹野一朗**.吉田 寛之**.笹瀬 雅人**.磯部 昭二**
}

（受理1994年12月 2 日，掲載決定1995年 2 月 4 日）

\author{
Formation of $\mathrm{Ti}-\mathrm{Al}-\mathrm{N}$ Thin Films by the Dynamic Ion Mixing Method \\ Ichiro TAKANO, Hiroyuki YOSHIDA, Masato SASASE and Shoji ISOBE
}

(Kogakuin University, Department of Electrical Engineering, 24-2, Nishi-shinjuku 1 chome, Shinjuku-ku, Tokyo 163-91)

(Received December 2, 1994, Accepted February 4, 1995)

\section{1. はじめに}

高速度工具鋼やダイス鋼のコーティングには低温処理 が可能な PVD法が多く用いられている。これらのコー ティングには TiN 系を主流とした積層膜が用いられて いるが，次世代の新膜物質として TiCN や TiNに $\mathrm{Al}$ を 添加した 2 成分系の窒化膜が実用化されてきている1). 特に TiAIN はTiCN に比べ硬さや耐摩耗性の点で劣る が, 耐食性, 耐熱酸化性に優れており切削工具, 金型の みならず装飾品などにも用いられつつある22.

これまでに筆者等は, ダイナミックミキシング法によ り TiNを形成しその特性を報告してきた ${ }^{3)}$. TiNの場 合には $\mathrm{Ti}$ 蒸着と同時に $\mathrm{N}_{2}^{+}$イオン照射することで膜を 形成したが, さらに $\mathrm{Al}$ 用の蒸着装置を追加設置するこ とで $\mathrm{Ti}-\mathrm{Al}-\mathrm{N}$ 膜形成を試みた。このように 2 源蒸着装 置を用いる方法は, TiAl 合金を用いる方法に比べ各成 分を任意に変化できるため多様性のある膜形成が行える と考えられる. 本研究では, TiAIN 薄膜の基礎データ 収集を目的とし，Nの含有量に対する硬さと摩擦係数 の変化, および $\mathrm{Al}$ と $\mathrm{Ti}$ の含有量を変えた場合の耐食性 の違いについて報告する.

\section{2. 実験方法}

Fig. 1 に電子ビーム加熱蒸着装置を 2 台設置したダイ ナミックミキシング装置 (日立製作所(侏) を示す. 蒸着

* 平成 6 年10月 28 日 第35回真空に関する連合講演会で講演

** 工学院大学（†163-91 東京都新宿区西新宿 1-24-2）
装置 1 には $\mathrm{Ti}$ を, 蒸着装置 2 には $\mathrm{Al}$ をセットすること で, 双方別々に蒸着速度をコントロールすることができ る. $\mathrm{Ti}$ と $\mathrm{Al}$ の蒸着速度は 2 台の水晶振動子型膜厚計で モニターしており，お互いの蒸着原子の影響を受けない ようにセンサ位置を調整し遮蔽板を設置してある. 試料 ホルダは基板表面の膜厚が均一になるように10 rpm で 回転させている，また，今回の成膜は室温で行ってい る.

実験に際しては, チャンバー内を $6 \times 10^{-4} \mathrm{~Pa}$ をで排 気した後, $\mathrm{N}_{2}^{+}$イン照射のための窒素ガスを $1.4 \times$ $10^{-2} \mathrm{~Pa}$ をで導入した。実験条件は Table 1 に示すよう に, $\mathrm{N}_{2}^{+}$イオン照射ェネルギー2, $5,10 \mathrm{keV}$, 照射電流 密度40〜80 $\mu \mathrm{A} / \mathrm{cm}^{2}, \mathrm{Al}$ と $\mathrm{Ti}$ の蒸着速度 $0.1 \sim 0.4 \mathrm{~nm} / \mathrm{s}$ の範囲でそれぞれ別々に変化した，なお，基板には鏡面

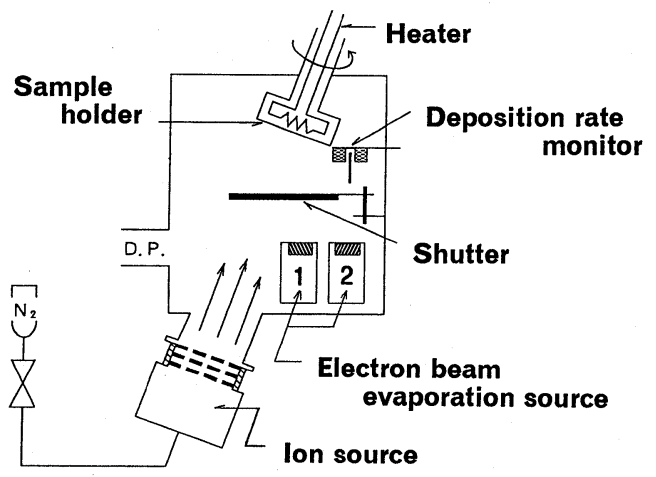

Fig. 1 Schematic diagram of the dynamic ion mixing apparatus. 
Table 1 Conditions of film preparation.

\begin{tabular}{l|l}
\hline \hline Base pressure & $6.0 \times 10^{-4} \mathrm{~Pa}$ \\
\hline $\mathrm{N}_{2}$ gas pressure & $1.4 \times 10^{-2} \mathrm{~Pa}$ \\
\hline $\mathrm{N}_{2}{ }^{+}$ion beam energy & $2,5,10 \mathrm{keV}$ \\
current & $40 \sim 80 \mu \mathrm{A} / \mathrm{cm}^{2}$ \\
\hline $\mathrm{Ti}, \mathrm{Al}$ evaporation rate & $0.1 \sim 0.4 \mathrm{~nm} / \mathrm{s}$ \\
\hline Film thickness & $\doteqdot 0.3 \mu \mathrm{m}$ \\
\hline
\end{tabular}

研磨したステンレス鋼（SUS304）を用いた。

形成膜については, $\mathrm{X}$ 線光電子分光装置 (ESCA$\mathrm{K} 1 \mathrm{~S}$ : 島津製作所(侏)）により Al2p と Ti2p スペクトルか ら組成および化学状態を決定した。 その際, $2 \mathrm{keV}, 20$ $\mu \mathrm{A}$ の $\mathrm{Ar}^{+}$イオンビームで試料表面を 4 分間スパッタ し, 表面から約 $10 \mathrm{~nm}$ の組成を試料の代表値として用い た。

形成膜の特性は, 硬さ試験, 摩擦摩耗試験, 耐食性試 験により評価した。硬さ試験は膜厚が約 $0.3 \mu \mathrm{m}$ である ことを考虑し， ヌープ圧子を用い負荷荷重 $3 \mathrm{gf}$ として 行った. 摩擦摩耗試験はピンオンディスク型試験機を用 いて行った．負荷荷重は100 gf, 回転速度 $135 \mathrm{rpm}$, 回 転半径 $5 \mathrm{~mm}$, 相手ピンには1/4インチの SUJ 球を使用 した。耐食性試験は $1 \mathrm{~mol} / \mathrm{dm}^{3}$ の $\mathrm{HCl}$ 溶液に対し, FFT アナライザ（アンリッ(侏）を用いた 2 電極交流イ ンピーダンス法により行った。この系を Grahame 等 ${ }^{4)}$ による最も簡単な等価回路で置き換え, $10 \mathrm{mHz} \sim 100$ $\mathrm{kHz}$ の周波数応答特性を測定した。周波数応答特性か ら耐食性を反映する界面通過抵抗 Rtを求め, それを評

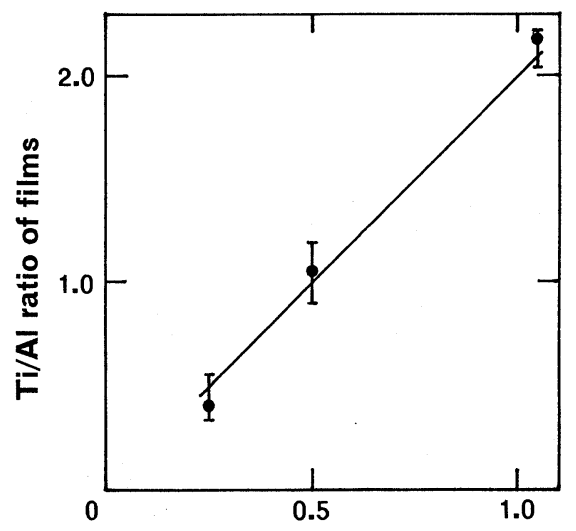

$\mathrm{Ti} / \mathrm{Al}$ evaporation- rate ratio

Fig. $2 \mathrm{Ti} / \mathrm{Al}$ ratio of prepared films versus $\mathrm{Ti} / \mathrm{Al}$ evaporation-rate ratio.

価対象とした.

\section{3. 実験結果および考察}

\section{1 薄膜の組成}

予備実験として $\mathrm{Ti}$ と $\mathrm{Al}$ を同じ蒸着速度で試料基板に 堆積させ組成を調べたところ， $\mathrm{Ti}$ と $\mathrm{Al}$ は等量存在する ことが確認された。これより, $\mathrm{Al}$ 蒸着速度 $0.2 \mathrm{~nm} / \mathrm{s}$, $\mathrm{Ti}$ 蒸着速度 $0.2 \mathrm{~nm} / \mathrm{s}$ で5 $\mathrm{keV}, 40 \mu \mathrm{A} / \mathrm{cm}^{2}$ の $\mathrm{N}_{2}^{+}$イオン 照射を行ったが，実際の組成は Ti 過剰となった。これ は, $\mathrm{N}_{2}^{+}$イオン照射により $\mathrm{Al}$ が $\mathrm{Ti}$ よりも多くスパッタ されるためと考えられる. Fig. 2 に示すように Ti/Al 蒸 着速度比が 0.5 のさ, 膜中の $\mathrm{Ti} / \mathrm{Al}$ 比がほぼ 1.0 となる
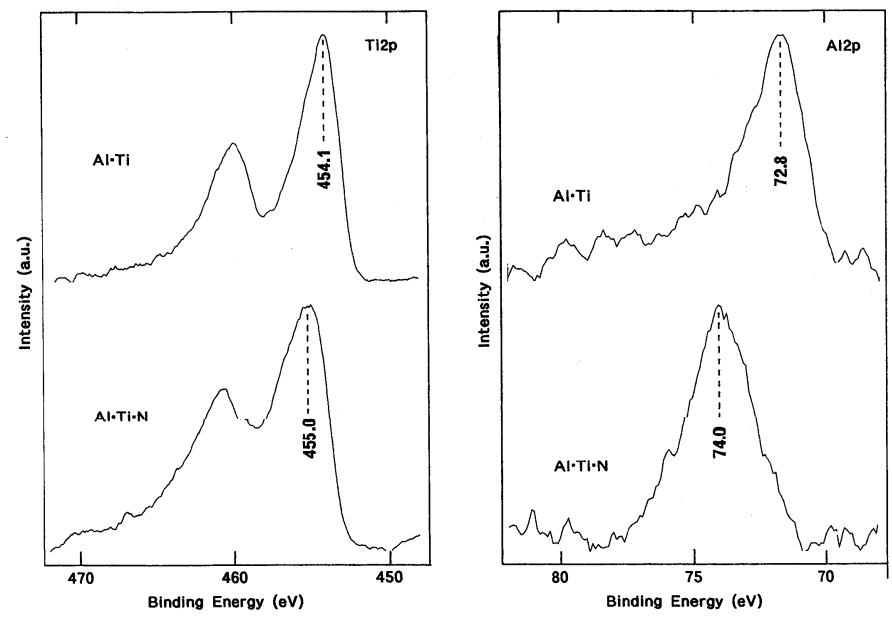

Fig. 3 XPS spectra of an Al2p and a Ti2p line for the $\mathrm{Ti}_{1.0} \mathrm{Al}_{1.0}$ and the $\mathrm{Ti}_{1.0} \mathrm{Al}_{1.0} \mathrm{~N}_{1.0}$ film. 


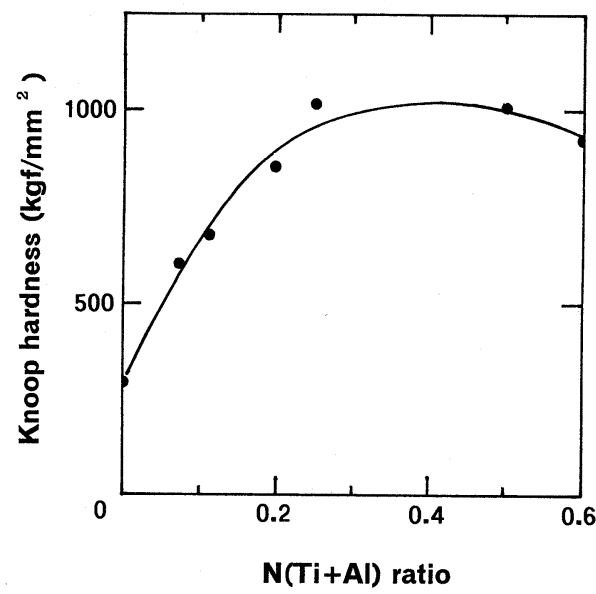

Fig. 4 Relation between $\mathrm{N} /(\mathrm{Ti}+\mathrm{Al})$ ratio and Knoop hardness with a load of $3 \mathrm{gf}$.

膜形成が行えた。このような条件の基で， $\mathrm{Ti}-\mathrm{Al}-\mathrm{N}$ の 各組成比が 1.0 となる膜組成は, $\mathrm{Al}: 30 \%, \mathrm{Ti}: 30 \%, \mathrm{~N}$ : $30 \%, \mathrm{O}: 5 \%, \mathrm{C}: 5 \%$ である. 不純物として, 酸素と炭 素が合わせて $10 \%$ 含まれているが, 以後 $\mathrm{Ti}, \mathrm{Al}, \mathrm{N}$ の組 成のみで論ずることとする。

Fig. 3 にはXPSによる Ti2p と Al2p スペクトル測定

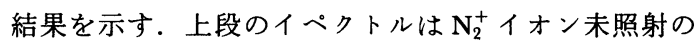
$\mathrm{TiAl}$ 蒸着膜（Ti/Al=1.0）である. $\mathrm{Al} 2 \mathrm{p}$ の結合エネル ギーについては, $72.8 \mathrm{eV}$ (TiAl) から74.0 eV (TiAlN) へのエネルギーシフトが，またTi2pについては454.1 $\mathrm{eV}$ (TiAl) から $455.0 \mathrm{eV}$ (TiAlN) へのエネルギーシフ トが確認できる。これらは窒化物である TiN および AlN の形成を裏付けるものであり， Ti 及び $\mathrm{Al}$ それぞれ が $\mathrm{N}$ と結合していることを示している.しかしながら， $\operatorname{TiN}(455.8 \mathrm{eV})$ と AlN $(74.4 \mathrm{eV})$ の結合エネルギーは ハンドブック值に比ベシフト幅が小さいことから， N 原子一つを $\mathrm{Ti}$ と $\mathrm{Al}$ が共有しているものと考えられる. 同様のことは，形成膜の N1s スペクトルの結合ェネル

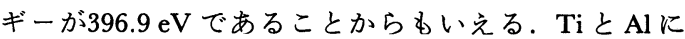
$\mathrm{N}_{2}^{+}$イオンを照射し TiNとAlNを形成を行った場合， $\mathrm{N} 1 \mathrm{~s}$ スペクトルの結合ェネルギーは $\mathrm{N}_{2}^{+}$イオン照射量と 共にシフトしおよそ397.5 eVになることがわかってい る. 以上のことから形成膜は TiN と AIN の混合物であ り，一つの $\mathrm{N}$ 原子を $\mathrm{Ti}$ と $\mathrm{Al}$ で共有していると推測さ れる.

\section{2 薄膜特性試験結果}

Fig. 4 には $\mathrm{N} /(\mathrm{Al}+\mathrm{Ti})$ 比に対する形成膜の硬さの変 化を示した. $\mathrm{N} /(\mathrm{Al}+\mathrm{Ti})$ 比が約 0.3 以上になるとヌープ 硬さは Hk1000で一定となる．このときの膜は $\mathrm{Al}_{1.0} \mathrm{Ti}_{1.0}$

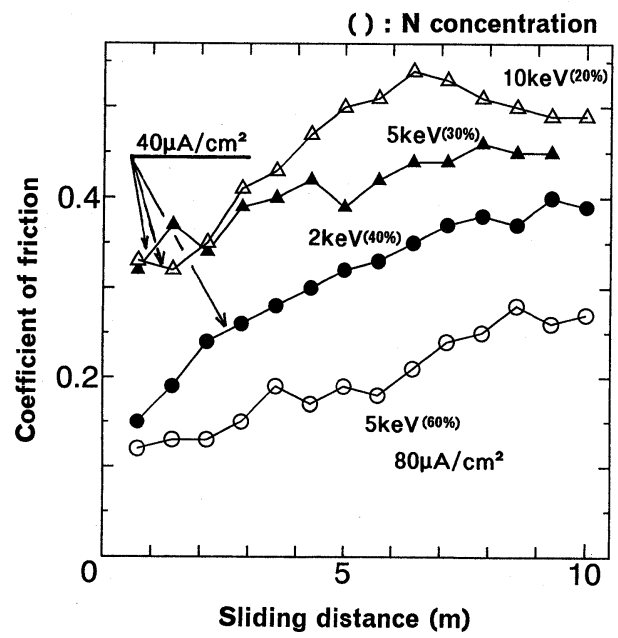

Fig. 5 Friction coefficient for $\mathrm{Ti}-\mathrm{Al}-\mathrm{N}$ films with various nitrogen concentrations prepared under several conditions.

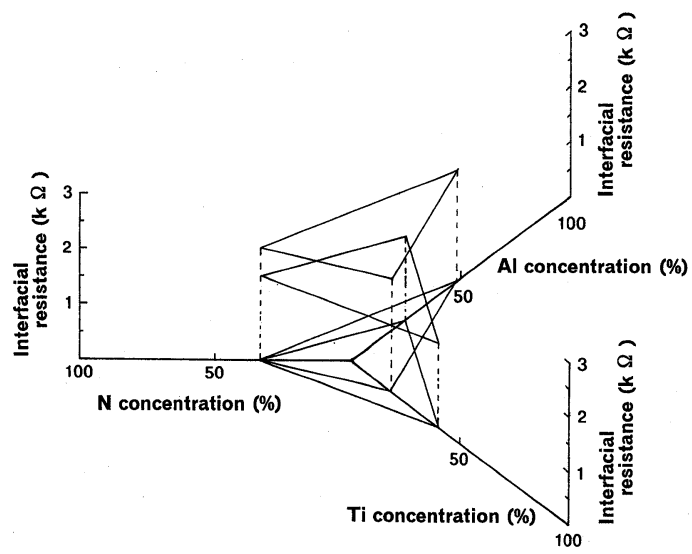

Fig. 6 Interfacial resistance measured by the AC impedance method for the $\mathrm{Ti}_{0.4} \mathrm{Al}_{0.26} \mathrm{~N}_{0.34}$ and the $\mathrm{Ti}_{0.18}$ $\mathrm{Al}_{0.48} \mathrm{~N}_{0.34}$ film with the different $\mathrm{Ti} / \mathrm{Al}$ concentration.

$\mathrm{N}_{1.0}$ であることから， N/ $(\mathrm{Al}+\mathrm{Ti})$ 比が 0.3 で硬さが最大 になったと考えられる．ただし， N/ $(\mathrm{Al}+\mathrm{Ti})$ 比が0.6に なると硬さは低くなる，これは窒素の含有量が増すこと による膜密度の低下に起因するものと考えられる．ま た，本実験での形成膜は膜厚が薄いため，本来の TiAlN 薄膜に比べ低い値を示している.

摩擦摩耗試験結果として摩擦距離に対する摩擦係数の 変化を Fig. 5 に示す. $\mathrm{N}_{2}^{+}$イオン電流密度を $40 \mu \mathrm{A} / \mathrm{cm}^{2}$ で一定とし，照射ェネルギーを $2,5,10 \mathrm{keV}$ に変えて形 成したそれぞれの試料は，エネルギーが小さくなるにつ 
れて摩擦係数が低くなる。これらの試料の $\mathrm{N}$ 濃度はそ れぞれ約20\%(10 keV)，30\%(5 keV)，40\%（2 keV) であることから， $\mathrm{N}$ 濃度の増加とともに摩擦係数は低 くなることがわかる。ささらにイオン照射ェネルギー 5 $\mathrm{keV}$, 電流密度 $80 \mu \mathrm{A} / \mathrm{cm}^{2}$ で形成した試料の $\mathrm{N}$ 濃度は約 $60 \%$ となり，最も低い摩擦係数を示した。

交流インピーダンス法による耐食性試験結果を Fig. 6 に示す。この試験では $\mathrm{N}$ 濃度を同じにして, Ti と Al

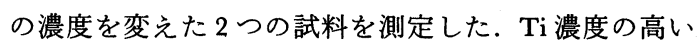
試料は $\mathrm{Ti}: 40 \%, \mathrm{Al}: 26 \%, \mathrm{Al}$ 濃度の高い試料は $\mathrm{Al}$ ： $48 \%, \mathrm{Ti}: 18 \%$ でどちらも $\mathrm{N}$ の濃度は34\%である。 $\mathrm{Ti}_{0.4} \mathrm{Al}_{0.26} \mathrm{~N}_{0.34}$ の試料の界面通過抵抗は1.5 k $\Omega$, これに 対し $\mathrm{Ti}_{0.18} \mathrm{Al}_{0.48} \mathrm{~N}_{0.34}$ の試料は $2.0 \mathrm{k} \Omega$ を示した. 基板材料 であるステンレス鋼の界面通過抵抗は $500 \Omega$ である.以 上のことから， $\mathrm{Al}$ の濃度を増すことによって，耐酸化 性が向上したものといえる。 また，一方でAlN は絶縁 物であるため, それによる効果も考えられる。このよう に $\mathrm{Al}$ と Ti の量を制御することで, TiN と $\mathrm{AlN}$ の長所 を活かした膜を作成することができる.

\section{4. ま め}

1） XPSの測定結果より, $\mathrm{Al}_{1.0} \mathrm{Ti}_{1.0} \mathrm{~N}_{1.0}$ のとき $\mathrm{Ti} 2 \mathrm{p}$
及び Al2pの化学結合ェネルギーは TiN及び AlN に対し化学シフトが小さかった。このことから， $\mathrm{Ti}$ と $\mathrm{Al}$ で一つの $\mathrm{N}$ 原子を共有していることが推 測される。

2) 膜中の $\mathrm{N} /(\mathrm{Al}+\mathrm{Ti})$ が増加すると膜の硬さ及び耐 摩耗性は向上する。これは窒化物の生成量に関係 している.

3） TiAlNの 3 成分の比を制御することで，耐食性 や耐摩耗性に優れた特長ある膜形成が可能と考え られる。

\section{謝 辞}

本実験を遂行するにあたり，試料基板であるステンレ ス鋼を提供くださった日金スチール(侏に感謝致します。

\section{〔文献〕}

1）新 成夫：溶接技術, 39 (1991) 91.

2）木道雄太郎, 池永 勝 : 型技術, 9 (1994) 31 .

3）鷹野一朗, 他 : 真空, 31 (1988) 529.

4) D. C. Grahame: J. Electrochem. Soci., 99 (1952) 370C. 